\title{
EFEITO DA ADIÇÃO DE AGENTES ANTIMICROBIANOIANTIFÚNGICO SOBRE DUREZA E RUGOSIDADE SUPERFICIAL DE CONDICIONADOR TECIDUAL
}

Vanessa Migliorini URBAN, Luciane Viriani PIZZATO, César Augusto Galvão ARRAIS, Rosangela Seiko SEO, Hercules Jorge ALMILHATTI

O efeito da incorporação de antifúngicos (nistatina-N, miconazol-M ou cetoconazol-K) ou antimicrobiano (diacetato de clorexidina-C) sobre propriedades físicas do condicionador tecidual Softone (S) foi determinado. Utilizou-se MEV/EDS para avaliar o padrão de incorporação destas drogas nas seguintes doses para $6 \mathrm{~g}$ de pó de $\mathrm{S}$ : $\mathrm{G} 1=$ controle (sem droga); G2= N-500.000U; G3= N-1.000.000U; G4= M-125mg; G5= M-250mg; G6=K-100mg; $\mathrm{G} 7=\mathrm{K}-200 \mathrm{mg} ; \mathrm{G} 8=\mathrm{C}-5 \%$ e G9= C-10\%. A dureza (Shore A) e rugosidade (Ra) das 135 amostras (36x7x6mm) foram determinadas após 24h, 7 e 14 dias de imersão em água. Os resultados foram analisados por 2-ANOVA/Tukey $(\alpha=0,05)$. Após os três períodos avaliados, a dureza dos grupos experimentais foi superior $(P<0,05)$ à do $G 1(7,48-15,56)$, com valores entre 10,56 (G5) e 21,26 (G2). Após 24h, a rugosidade do G3 $(6,66 \mu \mathrm{m})$ e G9 $(6,79 \mu \mathrm{m})$ foi superior $(\mathrm{P}<0,05)$ à do $\mathrm{G} 1(6,12 \mu \mathrm{m})$. Após 7 dias, apenas a rugosidade do $\mathrm{G} 4(6,07 \mu \mathrm{m})$ e $\mathrm{G} 6$ $(6,36 \mu \mathrm{m})$ foi igual $(P>0,05)$ à do $\mathrm{G} 1(5,83 \mu \mathrm{m})$. Após 14 dias, a rugosidade do $\mathrm{G} 5, \mathrm{G} 8$ e G9 foi

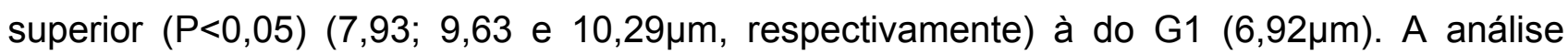
morfológica (MEV/EDS) demonstrou-se favorável para liberação intra-bucal das drogas. A significância das alterações observadas nas propriedades físicas deve ser clinicamente avaliada. 